cambridge.org/pax

\title{
Effects of a multidisciplinary quality of life intervention on sleep quality in patients with advanced cancer receiving radiation therapy - CORRIGENDUM
}

\section{Corrigendum}

Cite this article: Gentry MT et al. (2020). Effects of a multidisciplinary quality of life intervention on sleep quality in patients with advanced cancer receiving radiation therapy CORRIGENDUM. Palliative and Supportive Care 18, 374-374. https://doi.org/10.1017/ S147895151900083X
Melanie T. Gentry, M.D., Pamela J. Atherton, M.S., Maria Lapid, M.D., Preetha Sharone Rosen, M.D., Simon Kung, M.D., Jarrett Richardson, M.D., Shehzad K. Niazi, M.D., William V. Bobo, M.D., Matthew M. Clark, PH.D. and Teresa A. Rummans, M.D.

In the original publication of this article, the name of author Shehzad K. Niazi was misspelled. The original article has been corrected.

The authors apologize for this error.

\section{Reference}

Gentry MT, Atherton PJ, Lapid M, et al. (2019) Effects of a multidisciplinary quality of life intervention on sleep quality in patients with advanced cancer receiving radiation therapy. Palliative and Supportive Care, 1-7. doi:10.1017/S1478951519000750 